\title{
Prevalence and factors related to secondhand smoke exposure among secondary school-going adolescents in Malaysia: Findings from Malaysia Global Health School Survey 2012 and 2017
}

\author{
Kuang Hock Lim', Sumarni Mohd Ghazali', Hui Li Lim², Yoon Ling Cheong', Chee Cheong Kee, Pei Pei Heng', Tsye Yih \\ Tiunh', Mohd Hazilas Mat Hashim', Jia Hui Lim
}

\begin{abstract}
INTRODUCTION Secondhand (SHS) smoke exposure has caused various health problems. Therefore, continuous monitoring of SHS exposure is important to determine the efficacy of various anti-tobacco measure implemented. The study aims to compare the prevalence and factor(s) associated with SHS exposure among secondary school-going adolescents in Malaysia during 2012 and 2017. METHODS We derived data from the Global School Health Survey (GSHS) 2012 and GSHS 2017, which was carried out in Malaysia using multistage sampling to select representative samples of secondary school-going adolescents. Both surveys used similar questionnaires to measure SHS exposure. Descriptive and multivariate logistic regression was used to determine the prevalence and factors associated with SHS exposure.

RESULTS Approximately four in ten respondents were exposed to SHS in the past week in both surveys (41.5\% in GSHS 2012 and 42.0\% in GSHS 2017, respectively). Both surveys revealed a significantly higher SHS exposure among respondents who smoked than among non-smokers and higher among males compared to females. The likelihood of SHS exposure in both surveys was also similar, with a higher likelihood of SHS exposure among smoking adolescents and non-smoking adolescents who had at least one smoking parent/guardian, regardless of their own smoking status. Male adolescents had a higher risk of SHS exposure compared to their female counterparts. Meanwhile, SHS risk also increased with age, regardless of smoking status.

CONCLUSIONS Our findings suggested that there were no changes in the prevalence of SHS exposure and recorded only a slight change in the factors associated with exposure to SHS among school-going adolescents in Malaysia between the years 2012 and 2017. A more pro-active, extensive and comprehensive programme should be implemented to address the problem of SHS exposure. Parents should be advised to stop smoking or abstain from smoking in the presence of their children, and smoking cessation interventions are necessary for smoking adolescents and their parents.
\end{abstract}

\author{
AFFILIATION \\ 1 Institute for Medical \\ Research, National Institutes \\ of Health, Kuala Lumpur, \\ Malaysia \\ 2 Clinical Research Centre, \\ Hospital Sultan Ismail, Johor \\ Bahru, Malaysia \\ 3 Biostatistics and Data \\ Raspatory Sector, National \\ Institutes of Health, Shah \\ Alam, Malaysia \\ 4 Department of Pharmacy \\ and Pharmaceutical Sciences, \\ Monash University Malaysia, \\ Subang Jaya, Malaysia
}

CORRESPONDENCE TO Kuang Hock Lim. Institute for Medical Research, National Institutes of Health, Jalan Pahang, 50588 Kuala Lumpur, Malaysia. E-mail: keelimkota@yahoo.com

KEYWORDS

Malaysia Global Health School Survey, school-going adolescents, secondhand smoke

Received: 27 January 2021 Revised: 15 March 2021 Accepted: 22 April 2021

\section{INTRODUCTION}

Many studies have reported on the health-damaging effects of exposure to $\mathrm{SHS}^{1-3}$. Globally, about 0.6 million deaths were reported due to SHS, of which one-third were children ${ }^{4}$. SHS exposure has been shown to delay the neurodevelopment of youth and is significantly associated with poor academic achievement and neurocognitive performance among 
youth ${ }^{5}$. It is also caused lower respiratory illnesses middle ear disease in children, cough, phlegm, wheeze, and breathlessness among children of school age, ever having asthma, low birthweight, and a lower level of lung function during childhood ${ }^{6,7}$. Furthermore, SHS is also associated with an increased risk of middle ear effusion, adenoidectomy or tonsillectomy, atopyimmunoglobulin E-mediated allergy ${ }^{6,7}$, obstructive sleep apnea (OSA) among children and with single or multiple allergic morbidity ${ }^{8}$ and depressive symptoms ${ }^{9}$. Besides effects on health, SHS exposure also increases non-smokers susceptibility to smoking and reduces the likelihood of smoking cessation among young smokers ${ }^{10}$. Therefore, reducing SHS exposure are among the objectives stipulated in the national strategic plan for tobacco control in Malaysia $^{11}$.

In line with the objectives of the National AntiTobacco Strategic Plan and Article 8 of the Framework Convention on Tobacco Control (FCTC), which was ratified by the Malaysian government in $2005^{11}$, the Malaysian Ministry of Health has enacted the Control of Tobacco Products Regulations (CTPR) $2004^{12}$ which includes the provision of non-smoking areas in public places ${ }^{13}$. The CTPR 2004 has been amended several times to add more non-smoking areas. To date, more public areas have been gazetted as non-smoking areas ${ }^{13}$, among others, in: restaurants, workplaces with a centralized air-conditioning system; health, education, government and cultural facilities; and indoor stadiums. The Ministry of Health has also cooperated with the state governments to introduce the concept of non-smoking areas in selected localities, smoke-free Melaka (Melaka Bebas Asap Rokok, MBAR), smoke-free Penang (PBAR), smokefree Terengganu (TBAR) and Kelantan smokefree initiative (IKBAR) ${ }^{14}$. In addition, community interventions such as KOSPEN (Komuniti Sihat, Pembina Negara - Healthy Community, Developed the Nation) were launched in 2014 to address the higher prevalence of NCD risk factors which include encouraging the community to quit smoking and creating a smoke-free home ${ }^{15}$, in addition to health promotion activities in schools to provide awareness to youths about the dangers of tobacco smoke and legislation of smoke-free areas to protect non-smokers from exposure to SHS. Apart from that, the increase in smoking cessation activities among adults through a partnership of public and private practitioners would ensure Malaysia can achieve tobacco end-game by $2045^{11}$.

The Global School Health Survey conducted in Malaysia in 2012 among secondary school-going adolescents reported 4 out of 10 respondents were exposed to SHS in the past week ${ }^{16}$. The study found that the prevalence and likelihood of SHS exposure were higher among males, older adolescents, Malay and other Bumiputra ethnic group smokers, and adolescents who had smoking parents ${ }^{16}$. But measures implemented since 2012 such as community intervention programs ${ }^{15}$, expansion of non-smoking areas ${ }^{14}$, raising awareness of SHS through health promotion programs organized by Ministry of Health, Malaysia $(\mathrm{MOH})$ agencies and non-government organization (NGOs), and so on, may have changed the pattern of SHS exposure among adolescents ${ }^{15}$. Therefore, this study aims to describe the prevalence and factors related to exposure to SHS among secondary school-going adolescents in 2017 in comparison to 2012 .

\section{METHODS}

We derived data from the GSHS 2012 and GSHS 2017 surveys. Both surveys were cross-sectional, nationwide, school-based, and employed multistage sampling to select representative samples of the secondary school-going adolescents in Malaysia. The first stage of sampling was the stratification of each state in Malaysia, followed by the division of school locality by urban and rural areas for each state. The primary sampling units (schools) were selected in each state based on proportionate-to-size sampling, and three classes were randomly selected from each selected school by simple random sampling. All students in the selected classes were invited to participate in the study. The Ministry of Education (Malaysia) and State Education Department approved the protocol of the study, and the Medical Research Ethical Committee, Ministry of Health, Malaysia and the Ethical Committee of MOE have granted the ethical clearance for both surveys.

The active consent approach was used in both surveys to obtain permission from the respondents' parent or guardian. The consent form and an accompanying letter were distributed through the school administration to the family, and the parents/ 
guardian were informed of the objective of the study as well as the terms and conditions of participation in the study ${ }^{17}$. Only parents/guardian who consented were asked to return the filled form to the school administration. Prior to data collection, trained research team members have conducted a briefing session for the respondents to explain the objectives of the survey, the items in the questionnaire, their right to refuse to answer any of the questions, and the preservation of anonymity. Meanwhile, respondents have also fill in a consent form.

Similar items and definitions were used in both surveys. The dependent variable (exposure to SHS) was measured using the item: 'During the past seven days, on how many days did people smoke in your presence?'. Students who responded '0 days' were categorized as 'Not exposed to SHS', while those who answered ' $1-2$ days', ' $3-4$ days, ' $5-6$ days' or 'All 7 days' as exposed to SHS. The independent variables in both surveys are gender, age-group (13-15 years or $\geq 16$ years), smoking status (current smokers smoked at least once in the last 30 days), parental smoking status (neither, either mother or father, both parents), and ethnicity (Malay or other).

\section{Data management}

The data for the study were cleaned and weighted (taking into account the study design and poststratification weight). The characteristics of the respondents were expressed in percentages, and $95 \%$ confidence intervals were used to determine the significant differences in distribution by sociodemographic characteristics between both surveys. Chi-squared analysis was employed to test the associations between independent variables and the dependent variable (exposure to SHS). The independent variables in bivariate analysis with a p-value $\leq 0.25$ were included in a multivariable logistic regression model. All possible two-way interactions between the independent variables were checked. Significant interactions were found between gender and smoking status, smoking status and age, smoking status and parental smoking status. Hence, the multiple logistic regression model was stratified by smoking status and two separate models generated for each survey, one for smokers and another for nonsmokers. All statistical analyses were carried out at the $95 \%$ significance level using the complex samples module in SPSS statistics software version $20^{18}$.

\section{RESULTS}

The total number of respondents was 28758 and 30000 in GSHS 2012 and GSHS 2017, respectively. The response rates for GSHS 2012 and GSHS 2017 were $88.7 \%$ (25507) and 89\% (27497), respectively. The sociodemographic characteristics of respondents of the two surveys (gender, age group and ethnicity) were similar. The proportion of gender for both surveys was approximately equally distributed, with approximately 6 in 10 respondents aged 13-15 years and of Malay ethnicity. However, the proportion of current smokers and those who have at least one parent who smokes were significantly higher among GSHS 2017 survey respondents (Table 1).

Table 2 shows a significantly higher proportion of exposure to SHS among males, current smokers, at least one parent smokes, Malay ethnic, and aged $\geq 16$ years, in both surveys. A comparison of the SHS exposure for both surveys showed that SHS exposure was significantly lower among current adolescent

Table 1. Sociodemographic characteristics and parent/guardian smoking status of GSHS 2012 and GSHS 2017 respondents

\begin{tabular}{|c|c|c|c|c|c|c|}
\hline \multirow[t]{2}{*}{ Characteristics } & \multicolumn{3}{|c|}{ GSHS 2012} & \multicolumn{3}{|c|}{ GSHS 2017} \\
\hline & $\begin{array}{l}\text { Estimated } \\
\text { population }\end{array}$ & Sample & $\%(95 \% \mathrm{CI})$ & $\begin{array}{l}\text { Estimated } \\
\text { population }\end{array}$ & Sample & $\%(95 \% \mathrm{CI})$ \\
\hline \multicolumn{7}{|l|}{ Gender } \\
\hline Male & 1126613 & 12732 & $50.2(49.4-50.9)$ & 1064953 & 13135 & $49.6(48.9-50.4)$ \\
\hline Female & 1118911 & 12729 & $49.8(49.1-50.6)$ & 1081492 & 14362 & $50.4(49.6-51.1)$ \\
\hline \multicolumn{7}{|l|}{ Age (years) } \\
\hline $13-15$ & 1399022 & 16361 & $62.4(60.5-64.8)$ & 1302499 & 16952 & 60.7 (59.9-61.4) \\
\hline$\geq 16$ & 847958 & 9086 & $37.4(35.2-39.5)$ & 843946 & 10545 & $39.3(38.6-40.1)$ \\
\hline
\end{tabular}


Table 1. Continued

\begin{tabular}{|c|c|c|c|c|c|c|}
\hline \multirow[t]{2}{*}{ Characteristics } & \multicolumn{3}{|c|}{ GSHS 2012} & \multicolumn{3}{|c|}{ GSHS 2017} \\
\hline & $\begin{array}{l}\text { Estimated } \\
\text { population }\end{array}$ & Sample & $\%(95 \% \mathrm{CI})$ & $\begin{array}{l}\text { Estimated } \\
\text { population }\end{array}$ & Sample & $\%(95 \% \mathrm{CI})$ \\
\hline \multicolumn{7}{|l|}{ Ethnicity } \\
\hline Malay & 1366133 & 17086 & 60.8 (56.5-64.9) & 1354538 & 18713 & $63.1(62.4-63.8)$ \\
\hline Other & 880085 & 8378 & $39.2(35.41-43.5)$ & 791905 & 8784 & $36.9(36.2-37.6)$ \\
\hline \multicolumn{7}{|l|}{ Smoking status } \\
\hline Yes & 269079 & 2836 & 11.5 (10.4-12.7) & 295663 & 3595 & $13.8(13.3-14.2)$ \\
\hline No & 1981135 & 22671 & 88.0 (87.5-88.5) & 1850094 & 23892 & $86.2(85.7-86.7)$ \\
\hline \multicolumn{7}{|l|}{$\begin{array}{l}\text { At least one } \\
\text { parent/guardian } \\
\text { smoked }\end{array}$} \\
\hline Yes & 901410 & 10262 & $40.2(39.5-40.9)$ & 865381 & 11083 & $43.6(42.8-44.4)$ \\
\hline No & 1340356 & 15150 & $59.8(59.1-60.5)$ & 1120832 & 14510 & $56.4(55.6-57.2)$ \\
\hline
\end{tabular}

Table 2. Prevalence of secondhand smoke (SHS) among school-going adolescents by sociodemographic characteristics, and parent and respondents smoking status

\begin{tabular}{|c|c|c|c|c|c|c|}
\hline \multirow[t]{2}{*}{ Variable } & \multicolumn{3}{|c|}{ GSHS 2012} & \multicolumn{3}{|c|}{ GSHS 2017} \\
\hline & $\begin{array}{l}\text { Estimated } \\
\text { population }\end{array}$ & Sample & $\%(95 \% \mathrm{CI})$ & $\begin{array}{l}\text { Estimated } \\
\text { population }\end{array}$ & Sample & $\%(95 \% \mathrm{CI})$ \\
\hline \multicolumn{7}{|l|}{ Gender } \\
\hline Male & 560874 & 6257 & $50.0(47.7-52.3)$ & 524065 & 6435 & $49.3(48.2-50.4)$ \\
\hline Female & 371577 & 4345 & $33.2(31.6-34.9)$ & 376495 & 4950 & $34.9(33.8-37.9)$ \\
\hline \multicolumn{7}{|c|}{ Age (years) } \\
\hline $13-15$ & 506121 & 6007 & $36.4(34.8-38.1)$ & 483998 & 6203 & $37.2(36.3-38.1)$ \\
\hline$\geq 16$ & 427291 & 4607 & $50.0(47.5-52.6)$ & 416561 & 5182 & $49.4(48.2-50.7)$ \\
\hline \multicolumn{7}{|l|}{ Ethnicity } \\
\hline Malay & 647575 & 7926 & 47.5 (45.2-49.8) & 609364 & 8278 & $45.1(44.1-46.0)$ \\
\hline Other & 285271 & 2677 & $32.5(30.3-34.8)$ & 291196 & 3107 & $36.8(35.6-38.1)$ \\
\hline \multicolumn{7}{|c|}{ Smoking status } \\
\hline Yes & 221972 & 2360 & 86.9 (84.7-88.7) & 218363 & 2663 & $74.1(72.3-75.9)$ \\
\hline No & 705562 & 8186 & 35.7 (34.1-37.3) & 682197 & 8722 & $36.9(36.8-37.7)$ \\
\hline \multicolumn{7}{|c|}{$\begin{array}{l}\text { At least one } \\
\text { parent/guardian } \\
\text { smokes }\end{array}$} \\
\hline Yes & 506428 & 5784 & $56.3(54.4-58.2)$ & 521306 & 6646 & $60.3(59.1-61.4)$ \\
\hline No & 363071 & 4169 & 30.1 (28.4-31.9) & 314075 & 3934 & $28.0(27.1-29.0)$ \\
\hline
\end{tabular}

smokers, $74.1 \%$, (95\% CI: 72.3-75.9) in 2017 versus 86.9\% (95\% CI: 84.7-88.2) in 2012. However, the proportion of SHS exposure was significantly higher among respondents with at least one smoking parent in 2017 compared to 2012 (60.3\%, 95\% CI: 59.1-61.4 vs $56.3 \%, 95 \%$ CI: $54.4-58.2)$.
Multivariable analysis showed similar odds of SHS exposure among non-smoking adolescents in the two surveys, i.e. significantly higher among males, aged $\geq 16$ years, Malay ethnic, and had at least one parent who smoked. However, no similar pattern was observed of smoking adolescents, in which the odds of 
Table 3. Multiple logistic regression for the association between sociodemographic factors and SHS exposure in the GSHS-M 2012 and 2017

\begin{tabular}{|c|c|c|c|c|}
\hline \multirow[t]{2}{*}{ Variable } & \multicolumn{2}{|c|}{ GSHS 2012} & \multicolumn{2}{|c|}{ GSHS 2017} \\
\hline & $\begin{array}{c}\text { Smokers } \\
(n=2355) \\
\text { AOR }(95 \% \text { CI })\end{array}$ & $\begin{array}{l}\text { Non-smokers } \\
(n=21464) \\
\text { AOR }(95 \% \text { CI })\end{array}$ & $\begin{array}{c}\text { Smokers } \\
(n=2355) \\
\text { AOR }(95 \% \text { CI })\end{array}$ & $\begin{array}{c}\text { Non-smokers } \\
(n=21464) \\
\text { AOR }(95 \% \text { CI })\end{array}$ \\
\hline \multicolumn{5}{|l|}{ Gender } \\
\hline Male & $1.50(0.97-2.33)$ & $1.64(1.52-1.77)$ & $4.46(3.45-5.75)$ & $1.51(1.40-1.62)$ \\
\hline Female (Ref.) & 1 & 1 & 1 & 1 \\
\hline \multicolumn{5}{|l|}{ Age (years) } \\
\hline 13-15 (Ref.) & 1 & 1 & 1 & 1 \\
\hline$\geq 16$ & $2.32(1.55-3.48)$ & $1.77(1.61-1.96)$ & $2.22(1.75-2.82)$ & $1.83(1.69-1.98)$ \\
\hline \multicolumn{5}{|l|}{ Ethnicity } \\
\hline Malay & $1.76(1.21-2.54)$ & $1.72(1.48-2.02)$ & $1.01(0.80-1.28)$ & $1.31(1.21-1.43)$ \\
\hline Other (Ref.) & 1 & 1 & 1 & 1 \\
\hline \multicolumn{5}{|c|}{ At least one parent/guardian smokes } \\
\hline Yes & $1.62(1.14-2.30)$ & $3.03(2.73-3.33)$ & $3.07(2.45-3.85)$ & $4.19(3.88-4.52)$ \\
\hline No (Ref.) & 1 & 1 & 1 & 1 \\
\hline
\end{tabular}

AOR: adjusted odds ratio. Ref.: reference.

exposure were higher among smokers aged $\geq 16$ years and those with a smoking parent in both surveys. In 2017, the odds of SHS exposure were increased for male smokers, and smokers and non-smokers with at least one parent who smoked; however, the odds of SHS exposure were lower among Malays (Table 3).

\section{DISCUSSION}

\section{Prevalence of exposure to SHS}

The study revealed that SHS exposure in 2017 was $42.0 \%$, not significantly different from the prevalence in $2012^{16}$. However, this prevalence is lower than in two other Malaysian studies, i.e. $10 \%{ }^{19}$ and $16 \%$ lower ${ }^{20}$. In addition, this figure is also lower than the prevalence reported among middle and high school students in Kuwait (45.8\% and 51.6\%, respectively) ${ }^{21}$. Also, $\mathrm{Xi}$ et al. ${ }^{22}$ have reported a prevalence of $55.9 \%$ in 68 lower and low-income and middle-income countries, and $67.5 \%$ reported among youth in Vietnam $^{23}$. However, the prevalence of SHS is almost equal to the global estimated prevalence of $40 \%$ among children ${ }^{24}$ and $42 \%$ among youths in the state of Florida in the United States ${ }^{25}$. Gentzke et al. ${ }^{26}$ similarly reported no change in SHS exposure among middle and high school students from 2015 through 2017. This indicates that there has been no change in the smoking pattern in Malaysia during this period ${ }^{27}$ and the anti-tobacco measures that were implemented had not significantly impacted SHS exposure among youths. Due to that, more proactive steps that involve parents, schools and authorities should be formulated to achieve this objective.

\section{Factor(s) associated with SHS exposure}

Smokers were more likely to be exposed to SHS compared to non-smokers in a ratio of 2 to 1 in 2017, which was slightly reduced from 2.43 to 1 in 2012 . We postulate that this may be due to a decrease in the percentage of smokers who smoked with other smoking peers, therefore reducing the prevalence of SHS exposure by $12.6 \%$. However, this phenomenon persists among male adolescents, based on multivariate analysis and comparisons made with exposure in 2012. We further hypothesize that decreased smoking with peers is more significant among female smokers as the odds of being exposed to SHS were significantly higher among males in 2017 than in 2012, possibly because female smokers tend to smoke in private, as female smoking is not a norm in Malaysian society. In addition, Malaysia is a communal society, where the views of the society precede individual choice, presumably causing 
female smokers to smoke individually to avoid public censure $^{28}$. However, this theory needs to be confirmed through subsequent investigation in future studies. The study also found significantly lower prevalence and odds of SHS exposure among non-smokers, possibly because non-smokers have more knowledge on the hazards of $\mathrm{SHS}^{16,29}$ and have a negative attitude towards smokers ${ }^{23,30}$; they would therefore tend to avoid SHS exposure.

The odds of SHS exposure were also higher among non-smoking male adolescents, and this was in contrast with the findings of studies among students in Kuwait ${ }^{21}$, Saudi Arabia ${ }^{31}$ and the United States ${ }^{26}$. But, the results of our study are consistent with the findings of other local studies ${ }^{16,19-20}$. This finding may be explained by the higher prevalence of smoking among male adolescents in Malaysia and the tendency of males to mingle with other males; this might cause non-smoking male adolescents more likely to be exposed to SHS from their smoking peers.

Consistent with previous local ${ }^{16,19,20}$, and international studies ${ }^{22,26,32}$, the prevalence and odds of exposure to SHS were significantly higher among older adolescents (i.e. 16 and 17 years old), and this pattern has not changed since 5 years ago. This observation may be explained by the higher prevalence of smoking among adolescents from this age group, and in view of respondents tend to have same-age peers; this will increase the odds of exposure to SHS. In addition, parents and guardians tend to restrict their smoking behavior to protect young children, which diminishes for older children ${ }^{33,34}$. Furthermore, parents and guardians also provide more freedom to the respondents aged $\geq 16$ years compared to those aged 13-15 years. Therefore, they are more likely to patronize more public places such as bus stations, bistros, and therefore, the likelihood for them to be exposed to SHS is high, but our hypothesis needs to be tested in future studies.

Our study found that the prevalence and odds of exposure to SHS were significantly higher among school-going adolescents who have at least one parent/guardian who smokes; this finding is in congruence with the study of Sumarni et al. ${ }^{16}$ and systematic review by Orton et al. ${ }^{35}$. In addition, Park $^{36}$ also reported that concentrations of urine 4-(methylnitrosamino)-1-(3-pyridyl)-1-butanol (NNAL) were highest among children with smoking parents, almost 4 times compared to children with non-smoking parents and no SHS exposure at home (0.996 pg/mg, 95\% CI: 1.026-1.427). A comparison made on the prevalence and odds of exposure found a significant increase in 2017 compared to 2012 when one of the parent/guardians smoked. These findings suggested a possible displacement of smoking among adult smokers from public places into the home or into vehicles, although this phenomenon is not supported by the results of Lim et al. ${ }^{37}$ study comparing exposure rates at home between 2011 and 2015 . We postulate that this may be a relatively strict anti-smoking policy since 2015, such as the expansion of non-smoking areas in open eateries, which may have led to the findings in this study.

We found that the rate of SHS exposure among adolescents from Malay ethnicity was significantly high compared to their counterpart of non-Malays; the high prevalence of smoking among Malay adults and youth ${ }^{31,38}$ may be a possible explanation for the findings in our study. However, compared to 2012, there was a slight decrease in prevalence and odds of being exposed to SHS among Malay adolescents. This finding is encouraging, where Community Intervention such as KOSPEN implemented mainly in rural areas where the majority of the participants are Malay, and the 'Smoke-free home' element in the KOSPEN might have imparted knowledge and encouraged adult or adolescents smokers to smoke outside the house ${ }^{15}$. However, the findings of the lower odds of smokers and non-smokers of adolescents of Malay descent was also contributed by the increased prevalence of SHS exposure among non-Malays. This finding suggests further detail analysis should be carried out on SHS exposure to identify the ethnicity with higher prevalence of SHS exposure, and appropriate measures should be taken to address it.

\section{Strength and limitations}

Our study has several strengths. The GSHS 2012 and GSHS 2017 used standard procedures for selecting participants and the same questions, thus enabling the results between the surveys to be directly compared. Moreover, our study included a national representative large sample size, which enables the generalization of school-going adolescents in Malaysia.

Several limitations should also be noted. First, the use of tobacco products and exposure to secondhand 
smoke were self-reported, which might not necessarily reflect the true prevalence. However, studies have substantiated the validity of self-reported smoking in young adolescents using the objective measure of urinary cotinine and exhaled CO concentration ${ }^{39,40}$. Also, independent variables that have been shown to be significant in other studies, such as smoking status of household member, smoking status of peer ${ }^{41,42}$, knowledge of SHS health hazard and attitude towards smoking were not investigated ${ }^{30}$. Smoking restriction at home and location of exposure to SHS was also not determined. Therefore, the suitable measures that can be recommended to address SHS exposure in different settings cannot be formulated. Furthermore, there are some variables that show the characteristic differences of respondents that differ between 2012 and 2017 (i.e. smoking status and smoking status by parents) that may affect to some extent the comparisons made.

\section{CONCLUSIONS}

The study showed that SHS exposure among schoolgoing adolescents SHS did not change within the 5-year period between 2012 and 2017. This finding indicates that the measures and policies implemented were still not able to change the rate of SHS exposure. The results might be due to smoking patterns, and related aspects have not changed much in the Malaysian population. Therefore, proactive measures should be taken to reduce exposure to SHS among school-going adolescents. Parents and guardians who smoke should be advised not to smoke in front of their children. Meanwhile, programs should be designed to increase smoking cessation, among parents and respondents who smoke, through counselling or pharmacological assistance. In addition, more stringent enforcement of smoke-free public areas should be implemented by the relevant enforcement agencies. Future studies should include the variables that were identified as related to SHS exposure, frequency and location of SHS exposure, as well as awareness and attitude regarding SHS. Finally, the prevalence of SHS exposure is still high among school-going adolescents in Malaysia, especially among male, current smokers, older age group school-going adolescents, and schoolgoing adolescents with parent(s) who smoked.

\section{REFERENCES}

1. Office of Environmental Health Hazard Assessment.
Health effects of exposure to environmental tobacco smoke. California Environmental Protection Agency; 1997.

2. Institute of Medicine (US) Committee on Secondhand Smoke Exposure and Acute Coronary Events. Secondhand Smoke Exposure and Cardiovascular Effects: Making Sense of the Evidence. National Academies Press (US); 2010. doi:10.17226/12649

3. U.S. Department of Health and Human Services. The health consequences of involuntary smoking, a report of the Surgeon General. Publication No. 87-8398. 1986.

4. Oberg M, Jaakkola MS, Woodward A, Peruga A, PrussUstun A. Worldwide burden of disease from exposure to second-hand smoke: a retrospective analysis of data from 192 countries. Lancet. 2011;377:139-146. doi:10.1016/S0140-6736(10)61388-8

5. Chen R, Clifford A, Lang L, Anstey KJ. Is exposure to second-hand smoke associated with cognitive parameters of children and adolescents?-a systematic literature review. Ann Epidemiol. 2013;23(10). doi:10.1016/j.annepidem.2013.07.001

6. Tobacco Advisory Group of the Royal College of Physicians. Passive smoking and children. Royal College of Physicians; 2010.

7. US Office on Smoking and Health. The Health Consequences of Involuntary Exposure to Tobacco Smoke: A Report of the Surgeon General. US Centers for Disease Control and Prevention; 2006. Accessed January 11, 2021. https://www.ncbi.nlm.nih.gov/books/ NBK44324/

8. Subramanyam R, Tapia IE, Zhang B, et al. Secondhand Smoke exposure and risk of Obstructive Sleep Apnea in Children. Int J Pediatr Otorhinolaryngol. 2020;130:109807. doi:10.1016/j.ijporl.2019.109807

9. Jacob L, Smith L, Jackson SE, Haro JM, Shin JI, Koyanagi A. Second-hand Smoking and Depressive Symptoms Among In-School Adolescents. Am J Prev Med. doi:10.1016/j.amepre.2019.12.008

10. Okoli CT, Kodet J. A systematic review of secondhand tobacco smoke exposure and smoking behaviors: Smoking status, susceptibility, initiation, dependence, and cessation. Addict Behav. 2015;47:22-32. doi:10.1016/j.addbeh.2015.03.018

11. Malaysian Ministry of Health. National Strategic Plan on Tobacco Control 2015-2020: Strategic planning on smoking. Technical report in Malay. Malaysian Ministry of Health; 2014. Accessed January 2021. https://www. moh.gov.my/moh/resources/Penerbitan/Rujukan/NCD/ Tembakau/NSP_Tobacco_buku_bind_24oct2015.pdf

12. Government of Malaysia. Food act 1993: Control of tobacco product regulations. 2004.2005. In Malay. Accessed January, 2021. http://www.tobaccocontrollaws. org/files/live/Malaysia/Malaysia\%20-\%20TC\%20 Regs\%202004.pdf

13. Tobacco Control Laws. Legislation by country: Malaysia. 
Smoke Free Status of Indoor Public Places, Workplaces, and Public Transport. Accessed January 2021. https:// www.tobaccocontrollaws.org/legislation/country/ malaysia/sf-indoor

14. Lim KH, Lim HL, Teh CH, et al. Support for smokefree policy among Malaysian adults: findings from a population-based study. BMJ Open. 2019;9(2):e020304. doi:10.1136/bmjopen-2017-020304

15. Lim KH, M Fadhli Y, Omar M, et al. Technical Report Evaluation of Effectiveness of Implementation of "Komuniti Sihat Perkasa Negara" (Kospen) Programme In Malaysia- Phase 1. Institute of Public Health, Ministry of Health; 2014.

16. Ghazali SM, Huey TC, Cheong KC, et al. Prevalence and factors associated with second-hand smoke exposure among Malaysian adolescents. Tob Induc Dis. 2019;17(March). doi:10.18332/tid/102728

17. Institute for Public Health, Malaysian Ministry of Health. Tobacco \& E-Cigarette Survey Among Malaysian Adolescents (TECMA) 2016. Institute for Public Health; 2016. Accessed January 11, 2021. http://www.iku.gov. my/images/IKU/Document/REPORT/TECMA2016/ TabaccoandECigarette.pdf

18. IBM SPSS Statistics. Version 20.0. IBM Corp; 2011.

19. Abidin EZ, Semple S, Omar A, Rahman HA, Turner SW, Ayres JG. A survey of schoolchildren's exposure to secondhand smoke in Malaysia. BMC Public Health 2011;11:634. doi:10.1186/1471-2458-11-634

20. Lim HL, Teh CH, Kee CC, Mohd Ghazali S, Pan S a/l, Lim KH. Exposure to second-hand smoke among secondary school-going adolescents: Findings from the Malaysian Adolescent Health Risk Behaviour (MyAHRB) study. Proceedings of Singapore Healthcare. 2019;28(1):19-25. doi:10.1177/2010105818789961

21. Ziyab AH, Almari M, Al-Taiar A. Exposure to household secondhand smoke among adolescents in Kuwait: Results from two school-based cross-sectional studies. Tob Induc Dis. 2020;18(April). doi:10.18332/tid/119116

22. Xi B, Liang Y, Liu Y, et al. Tobacco use and secondhand smoke exposure in young adolescents aged 1215 years: data from 68 low-income and middle-income countries. Lancet Glob Health. 2016;4:e795-e805. doi:10.1016/S2214-109X(16)30187-5

23. Lee JY, Ahn H, Lee H. Factors Affecting Secondhand Smoke Avoidance Behavior of Vietnamese Adolescents. Int J Environ Res Public Health. 2018;15(8):1632. doi:10.3390/ijerph15081632

24. Veeranki PS, Mamudu HM, Zheng S, et al. Secondhand smoke exposure among never-smoking youth in 168 countries. J Adolesc Health. 2015;56(2):167-173. doi:10.1016/j.jadohealth.2014.09.014

25. Bayly JE, Bernat D, Porter L, O’Dare K, Choi K. Prevalence and characteristics of secondhand smoke and secondhand vapour exposure among youth. Tob Control. 2019;28(3):305310. doi:10.1136/tobaccocontrol-2018-054265
26. Gentzke AS, Wang TW, Marynak KL, Trivers KF, King BA. Exposure to Secondhand Smoke and Secondhand E-Cigarette Aerosol Among Middle and High School Students. Prev Chronic Dis. 2019;16:E42. doi:10.5888/pcd16.180531

27. Lim KH, Teh CH, Pan S, et al. Prevalence and factor/s associated with smoking among adults in Malaysia - Findings from the National Health and Morbidity Survey (NHMS) 2015. Tob Induc Dis. 2018;16(January). doi:10.18332/tid/82190

28. Lim KH, Lim HL, Teh CH, et al. Smoking among schoolgoing adolescents in selected secondary schools in Peninsular Malaysia- findings from the Malaysian Adolescent Health Risk Behaviour (MyaHRB) study. Tob Induc Dis. 2017;15(January). doi:10.1186/s12971-016-0108-5

29. Ding D, Wahlgren DR, Liles S, Jones JA, Hughes SC, Hovell MF. Secondhand smoke avoidance by preteens living with smokers: To leave or stay? Addict Behav. 2010;35:989-994. doi:10.1016/j.addbeh.2010.06.016

30. Al Omari O, Abu Sharour L, Heslop K, et al. Knowledge, Attitudes, Prevalence and Associated Factors of Cigarette Smoking Among University Students: A Cross Sectional Study. J Community Health. 2020. doi:10.1007/s10900-020-00874-0

31. Al-Zalabani AH, Amer SM, Kasim KA, Alqabshawi RI, Abdallah AR. Second-Hand Smoking among Intermediate and Secondary School Students in Madinah, Saudi Arabia. Biomed Res Int. 2015:672393. doi:10.1155/2015/672393

32. Mlinarić M, Schreuders M, Mons U, Kunst AE. Exposure to car smoking among youth in seven countries of the European Union. Eur J Public Health. 2019;29(Supplement_4). doi:10.1093/eurpub/ckz185.606

33. Ossip DJ, Chang Y, Nabi-Burza E, et al. Strict smokefree home policies among smoking parents in pediatric settings. Acad Pediatr. 2013;13(6):517-523. doi:10.1016/j.acap.2013.06.003

34. Nor Syazwani S, Sri Ganesh M, Hayati K. Determinants of Voluntary Smoke- Free Home Among NonSmoking Women in Alor Gajah, Melaka. Mal J Med Health Sci. 2019;15(SP3):70-76. Accessed January, 2021. https://medic.upm.edu.my/upload/ dokumen/2019110412131111_MJMHS_0233.pdf

35. Orton S, Jones LL, Cooper S, Lewis S, Coleman T. Predictors of children's secondhand smoke exposure at home: A systematic review and narrative synthesis of the evidence. PLoS One. 2014;9:e112690. doi:10.1371/journal.pone.011269036.

36. Park MB. Living with parents who smoke predicts levels of toxicant exposure in children. Sci Rep. 2020;10(1):11173. doi:10.1038/s41598-020-66920-y

37. Lim KH, Lim HL, Teh CH, et al. Secondhand smoke (SHS) exposure at home and at the workplace among non-smokers in Malaysia: Findings from the Global Adult Tobacco Survey 2011. Tob Induc Dis. 2018;16(October). doi:10.18332/tid/95188 
38. Ling MYJ, Rodzlan Hasani WS, Mohd Yusoff MF, et al. Gigarette Smoking Among Secondary SchoolGoing Male Adolescents In Malaysia: Findings From The National Health and Morbidity Survey 2017. Asia Pac J Public Health. 2019;31(8_suppl). doi:10.1177/1010539519874948

39. Manan NA, Nawi AM, Ahmad N, Hassan MR. Selfreported smoking among adolescents: How accurate is it with the urine cotinine strip test?. Int J Pediatr Adolesc Med. 2020;7(2):78-82. doi:10.1016/j.ijpam.2019.08.001

40. Lim HL, Teh CH, Kee CC, Normala I, Lim KH. Do adolescents under-report their smoking status? - Findings from secondary school students in Kota Tinggi, Johor. International Journal of Public Health and Clinical Sciences. 2017;4(2):66-72. Accessed January 11, 2021. http://publichealthmy.org/ejournal/ojs2/index.php/ ijphcs/article/view/400/358

41. Phetphum C, Noosorn N. Prevalence of second-hand smoke exposure at home and associated factors among middle school students in Northern Thailand. Tob Induc Dis. 2020;18(February). doi:10.18332/tid/117733

42. Alves RF, Precioso J, Becona E. Smoking behavior and second-hand smoke exposure among university students in northern Portugal: Relations with knowledge on tobacco use and attitudes toward smoking. Pulmonology. 2020. doi:10.1016/j.pulmoe.2020.03.004
ACKNOWLEDGEMENTS

We thank the Director-General of Health Malaysia for his permission to publish this article.

\section{CONFLICTS OF INTEREST}

The authors have completed and submitted the ICMJE Form for Disclosure of Potential Conflicts of Interest and none was reported.

\section{FUNDING}

The Public Health Institute, Ministry of Health Malaysia provided funding for this research.

\section{ETHICAL APPROVAL AND INFORMED CONSENT}

The Ministry of Education (Malaysia) and State Education Department approved the protocol of the study, and the Medical Research Ethics Committee, Ministry of Health, Malaysia and the Ethics Committee of MOE have granted the ethical clearance for both surveys (16.3.16, NMRR-16-698-30042). The active consent approach was used in both surveys to obtain permission from the respondents' parent or guardian.

\section{AUTHORS' CONTRIBUTIONS}

KHL and HLL contributed to the conception of the study. SMG, YLC, JHL, TYT, MHMH and CCK contributed significantly to analysis and manuscript preparation. KHL, HLL, CCK and JHL contributed to critically revising the manuscript. All authors read and approved the final manuscript.

PROVENANCE AND PEER REVIEW

Not commissioned; externally peer reviewed. 